\title{
O PARFOR E A REFLEXÃO SOBRE A PRÁTICA DAS PROFESSORAS: A FORMAÇÃO PROFISSIONAL DAS ALFABETIZADORAS
}

Darciane Vieira Barros ${ }^{1}$ Nandyara Souza Santos ${ }^{2}$

RESUMO: O trabalho resulta de uma pesquisa realizada a fim de cumprir parte dos requisitos do curso de graduação em Pedagogia na Universidade Estadual do Sudoeste da Bahia, referente à disciplina Trabalho de Conclusão de Curso, que teve como objeto de pesquisa o papel do PARFOR no desenvolvimento profissional de professores alfabetizadores. Neste sentido, utilizamos a seguinte questão de pesquisa: como o PARFOR contribuiu com a formação profissional dos professores alfabetizadores? Para analisar tal questão, utilizamos entrevistas semi-estruturadas como instrumento principal de investigação, o que nos possibilitou, através da obtenção dos relatos dos cinco sujeitos da pesquisa, professoras graduandas em Pedagogia pelo PARFOR/UESB, polo de Jaguaquara/BA, conhecer a contribuição do referido curso na revisão da prática desses professores alfabetizadores. Desta forma, a referida pesquisa nos oportunizou conhecer algumas contribuições, segundo as percepções das participantes da investigação, do curso de Pedagogia como: as reflexões dos docentes sobre a sua prática e a possibilidade de relacioná-la com a teoria, assim como a aquisição de novos saberes pelos professores, que aprenderam a enxergar os discentes e os seus processos de aprendizagem de forma diferente, como veremos nesse estudo.

Palavras-Chave: Formação Continuada; Parfor; Professor Alfabetizador.

ABSTRACT: The present work is the result of a research carried out in order to fulfill part of the requirements of the undergraduate course in Pedagogy, at the State University of Southwest Bahia, referring to the subject "Final Work for the Undergraduation", which had as object of research the role of PARFOR in the professional development of literacy teachers. In this regard, we used the following research question: how did PARFOR contribute to the professional training of literacy teachers? To analyze this issue, we used semi-structured interviews as the main research instrument, which enabled us, through obtaining the reports of the five research subjects, graduate teachers in Pedagogy by PARFOR/UESB, in Jaguaquara/Bahia, to know the contribution of that course in reviewing the practice of literacy teachers. Thus, the referred research gave us the opportunity to know some contributions, according to the perceptions of the research participants, of the Pedagogy course, such as: the teachers' reflections on their practice and the possibility of relating it to the theory, as well as the acquisition of new knowledge by teachers, who learned to see students and their learning processes differently, as we will see in this study.

Key words: Continuing Education; Parfor; Literacy Teacher.

\section{Introdução}

Tendo em vista que este trabalho é destinado a tratar da profissão do professor alfabetizador, é imprescindível reiterar que a alfabetização, não só no Brasil, mas no mundo

\footnotetext{
${ }^{1}$ Graduada em Pedagogia. Universidade Estadual do Sudoeste da Bahia, Campus Jequié/BA. E-mail: <darcianebarros@hotmail.com>.

${ }^{2}$ Orientadora. Professora da Universidade Estadual do Sudoeste da Bahia. Graduação em Pedagogia (UESB, 2002). Mestre em Educação (UEFS, 2015). E-mail: <nandyarass@gmail.com>.
} 
- Revista de Iniciação à Docência, v. 5, n. 3, 2020 -

Publicação: março, 2021 - ISSN 2525-4332

como um todo, é uma temática complexa, considerando o seu constante fracasso anualmente verificado em milhares de classes de alfabetização espalhadas pelo território nacional, resultado da não aprendizagem da leitura e da escrita por crianças em idade escolar. No Brasil, até o ano de 2017, constatamos que 7,5\% da população acima de 15 anos é caracterizada como analfabeta, o que corresponde a 11,8 milhões de pessoas não alfabetizadas no país, de acordo com dados do Instituto Brasileiro de Geografia e Estatísticas (IBGE).

Destarte, é dessa realidade que surgiu o interesse pelo assunto pesquisado neste trabalho que, para além da realidade dos discentes, há muito conhecida, avançou em busca de outros sujeitos importantes no cenário dos processos de alfabetização: os professores. Mas, não foram quaisquer professores, mas sim, professores atuantes há anos em salas de aulas e que só atualmente, 25 anos após a promulgação da LDB - Lei n. 9.394/96, documento legal que instituiu a exigência da formação docente em nível superior, tivessem a oportunidade de "sentarem nos bancos" da universidade para compreenderem, refletirem ou reverem os seus conceitos sobre o direito das crianças de aprender e sobre o papel dos educadores frente a essa realidade.

Diante disso, nosso trabalho, resultado de uma pesquisa nascida do interesse profundo pela alfabetização, teve como objetivo conhecer como o PARFOR 3 contribuiu para a formação profissional dos professores alfabetizadores, utilizando para isso algumas questões norteadoras, dentre as quais destacamos as seguintes: i) de que maneira a formação profissional obtida no PARFOR possibilitou a revisão das práticas dos professores?; ii) como a formação profissional oferecida contribuiu para a construção de saberes docentes voltados para o processo de alfabetização dos estudantes?

\section{A formação de professores}

A necessidade de formar professores surge, de maneira institucionalizada, no século XIX, mais precisamente na França, motivada pela questão da instrução popular. A instituição pioneira a oferecer essa formação recebeu o nome de Escola Normal e foi inaugurada no ano de 1795, na cidade de Paris, distinguindo-se, a partir desse momento, da Escola Normal Superior - que formava educadores de nível secundário - e da Escola Normal Primária, dedicada à formação dos professores para o ensino primário (SAVIANI, 2009).

No Brasil, essa formação é iniciada após a independência e, semelhantemente ao modelo europeu, surgiu devido à necessidade de formar professores para atuarem na instrução popular. Dessa forma, podemos perceber, em concordância com Gatti (2010), que desde o século XIX a formação docente já acontecia nas Escolas Normais. No entanto, foi só a partir da LDB, Lei n. 9.394/96 (BRASIL, 1996), que surge a preocupação com a formação desses profissionais em nível superior, visto que até esse momento ela acontecia

\footnotetext{
${ }^{3}$ PARFOR: Plano Nacional de Formação de Professores da Educação Básica.
} 
- Revista de Iniciação à Docência, v. 5, n. 3, 2020 -

Publicação: março, 2021 - ISSN 2525-4332

predominante em nível médio. A referida Lei trata, em seu art. 62, sobre a formação de professores, assinalando que:

\begin{abstract}
A formação de docentes para atuar na educação básica far-se-á em nível superior, em curso de licenciatura plena, admitida, como formação mínima para o exercício do magistério na educação infantil e nos cinco primeiros anos do ensino fundamental, a oferecida em nível médio, na modalidade normal (BRASIL, 1996).
\end{abstract}

Em vista disso, os profissionais que outrora possuíam apenas a formação em nível médio, tiveram prazo fixado em 10 anos para efetivar o complemento de formação proposto pela Lei. No entanto, apesar de instituir a necessidade de formação em nível superior para todos os professores, a referida Lei gerou certa ambiguidade, permitindo que a formação em magistério continuasse sendo exercida, tendo, porém, um prazo estabelecido para o seu final.

Porém, passados mais de 20 anos da promulgação desse marco legal, é possível encontrar inúmeros professores ainda com déficit de formação, mesmo com o surgimento de políticas públicas voltadas para a formação desses profissionais. Isso mostra a ineficiência das políticas para a formação docente, visto que os sistemas de ensino (estaduais e municipais) ainda não conseguiram contemplar plenamente o que determina o referido dispositivo legal.

\title{
3. O Plano Nacional de Formação de Professores da Educação Básica (PARFOR)
}

O PARFOR é uma ação da Coordenação de Aperfeiçoamento de Pessoal de Nível Superior (CAPES) que tem como objetivo contribuir com a oferta de educação superior para os profissionais do magistério que ainda não possuam formação específica na área de sua atuação em sala de aula (BRASIL, 2018). A CAPES é uma fundação vinculada ao Ministério da Educação (MEC), criada em 1951, pelo renomado educador Anísio Teixeira, a qual possui reconhecimento nacional e internacional devido à sua atuação junto ao Sistema Nacional de Pós-Graduação. No entanto, na concepção original de Anísio Teixeira, ao criar a CAPES, a ideia não seria apenas ter como prioridade a Educação Superior, mas sim também dar apoio às carências da Educação Básica (BRASIL, 2014).

Dessa forma, após 56 anos de sua criação, a CAPES passou a realizar ações conforme o seu objetivo inicial, a partir da aprovação da Lei n. 11.502/2007 (BRASIL, 2007), homologada pelo então presidente Luís Inácio Lula da Silva, em julho de 2007, que conferiu à CAPES a responsabilidade de induzir e fomentar a formação inicial e continuada de professores para a Educação Básica (BRASIL, 2014).

Com essa responsabilidade, a CAPES fomenta há quase 10 anos, através do PARFOR, cursos de educação superior voltados para profissionais ainda sem formação superior que diariamente atuam na Educação Básica, conforme prevê a LDB. Esses cursos são oferecidos em três modalidades: primeira licenciatura; segunda licenciatura; formação pedagógica; os quais são cursos ofertados em Institutos de Educação Superior do país. 
Voltados para um público específico, cada curso possui uma finalidade. O curso de licenciatura é indicado para professores da rede pública que não possuem formação em nível superior. O curso de segunda licenciatura deve ser ofertado para os docentes que já cursaram alguma licenciatura e, no entanto, atuam nas escolas em uma área distinta daquela em que foi formado. A formação pedagógica destina-se para professores que já possuem curso superior, mas que não têm a habilitação em licenciatura (BRASIL, 2018). Em que pesem tais questões estarem preconizadas no documento, o que se verifica é a formação de turma única, na qual primeira e segunda licenciatura funcionam juntas.

Dessa forma, o PARFOR, desde 2009, ano em que foi criado, tem atuado na oferta de formação inicial a diversos docentes que atuam na educação básica e carecem da formação específica no Ensino Superior, tendo formado 44.843 professores até o ano de 2018, embora mais de 94 mil pessoas tenham se matriculado entre os anos de 2009 e 2016. Outros 22.506 professores-estudantes estavam cursando licenciaturas até maio de 2018, de acordo com dados divulgados pela CAPES (BRASIL, 2018).

Em seus objetivos pretende-se, além de fomentar a oferta da Educação Superior, "promover a articulação entre as instituições formadoras e as secretárias de educação para atender as necessidade da formação de professores"4 e a contribuição para o alcance da Meta 15 do Plano Nacional de Educação, referente ao cumprimento da Lei n. 9.394/96, no que se refere à formação de professores, além de outras propostas que visam beneficiar os docentes da Educação Básica que precisam aprimorar sua formação (BRASIL, 2018).

\section{Saberes docentes}

Ao tratarmos da profissão docente é imprescindível discutirmos aspectos sobre os saberes que servem de base ao ofício de professor, considerando que eles não se resumem a um único saber, mas a uma diversidade de saberes. Neste sentido, Tardif (2014) traz alguns esclarecimentos sobre os diferentes saberes necessários para a profissão docente, dentre os quais podemos citar: os saberes da formação profissional, os saberes disciplinares, os saberes curriculares e os saberes experienciais. A seguir apresentaremos alguns detalhes sobre tais saberes, compreendendo melhor as suas diferenças e singularidades. Antes de mais nada, é importante ressaltar que o saber, segundo Tardif (2014, p. 11):

É sempre o saber de alguém que trabalha alguma coisa no intuito de realizar um objetivo qualquer. Além disso, o saber não é uma coisa que flutua no espaço: o saber dos professores é o saber deles e está relacionado com a pessoa e a identidade deles, com a sua experiência de vida e com a sua história profissional com as suas relações com os alunos em sala de aula e com os outros atores escolares na escola, etc. Por isso, é necessário estudá-lo relacionando-o com esses elementos constitutivos do trabalho docente.

\footnotetext{
4 Trecho retirado do Plano Nacional de Formação dos Professores - PARFOR.

Disponível em: <http://www.capes.gov.br/educacao-basica/parfor>. Acesso: 14 de mai. 2020.
} 
- Revista de Iniciação à Docência, v. 5, n. 3, 2020 -

Publicação: março, 2021 - ISSN 2525-4332

Portanto, quando nos referimos aos saberes docentes, precisamos levar em conta a identidade dos seus profissionais, considerando que eles possuem sonhos, diferentes perspectivas e uma história de vida, os quais influenciam a forma como esses profissionais ensinam e exercem suas práticas. Assim, as experiências que são adquiridas pelos professores não se dão apenas ao longo de sua formação, mas também durante as suas vidas e contribuem para a construção dos seus saberes. Diante do exposto, prossigamos na definição dos quatro diferentes saberes discutidos por Tardif (2014). Tais elementos se apresentam como essenciais para compreensão desta seção, desvelando esclarecimentos relevantes sobre as diferentes visões concebidas aos saberes que constituem a profissão docente e que fazem parte do universo desses profissionais.

Os saberes da formação profissional dizem respeito a um conjunto de saberes baseados na ciência e transmitidos aos professores durante a sua formação, quando eles têm contato com as ciências da educação que, por sua vez, dão o suporte basilar a sua prática. Por isso, esse conjunto de saberes também pode ser considerado como associados aos conhecimentos pedagógicos que, de acordo com o autor, se apresentam como doutrinas ou concepções de reflexões sobre a prática educativa, os quais representam as técnicas e os métodos de ensinar aprovados pela ciência e difundidos durante o processo formativo (TARDIF, 2014).

Os saberes disciplinares são caracterizados por pertencerem aos diversos campos do conhecimento (Matemática, História, Literatura, Ciências Naturais), que correspondem aos saberes historicamente construídos e acumulados pela sociedade, os quais também são transmitidos através do processo educacional por meio das disciplinas, nos cursos e nas universidades, que não correspondem apenas às faculdades de educação, mas, estão presentes em todas as modalidades de ensino, independente se o objetivo for formar professores (TARDIF, 2014). Já os saberes curriculares referem-se a discursos, conteúdos, métodos e objetivos que são utilizados pelas instituições escolares para transmitir os saberes sociais (saberes disciplinares), que são definidos por essas instituições e devem ser aprendidos e aplicados pelos professores, a fim de formar culturalmente os alunos (TARDIF, 2014).

Por fim, os saberes experienciais correspondem aos saberes construídos pelos próprios professores, através da sua prática cotidiana: "eles incorporam-se à experiência individual e coletiva sob a forma de habitus e de habilidades, de saber-fazer e de saber-ser" (TARDIF, 2014, p. 39); podem também ser chamados de saberes práticos, tendo em vista a forma como são construídos, correspondendo não só o trabalho na prática, mas na relação entre momentos específicos da prática e os conhecimentos individuais dos professores (TARDIF, 2014).

Assim, como foi possível perceber, a prática docente está entrelaçada por estes muitos saberes, sendo, na verdade, os elementos que a constituem. A partir de tal perspectiva, diante de todos esses saberes, o professor ideal, de acordo com Tardif (2014, p. 39): 
- Revista de Iniciação à Docência, v. 5, n. 3, 2020 -

Publicação: março, 2021 - ISSN 2525-4332

É alguém que deve conhecer a sua matéria, sua disciplina e seu programa, além de possuir certos conhecimentos relativos às ciências da educação e à pedagogia e desenvolver um saber prático baseado em sua experiência cotidiana com os alunos.

Dessa forma, os saberes devem ser levados em conta pelos professores, considerando que cada um deles possui importância e serve para aprimorar a prática docente. Além disso, é necessário o entendimento de que a função do professor não está relacionada somente a um simples procedimento de transmissão de conhecimentos, como reitera o autor citado, pois, dialogando com Gauthier et al. (2006, p. 20-21):

Pensar que ensinar consiste apenas em transmitir um conteúdo a um grupo de alunos é reduzir uma atividade tão complexa quanto o ensino a uma única dimensão, aquela que é mais evidente, mas é sobretudo negar-se a refletir de forma mais profunda sobre a natureza desse ofício e dos outros saberes que lhe são necessários.

Isto posto, entendemos, em concordância com os autores como Gauthier et al. (2006), que o ato de ensinar se constitui como uma atividade complexa. Não basta aos professores apenas conhecerem os conteúdos, ter talento para ensinar, possuir bom senso ou simplesmente ter experiência. É necessário que eles mobilizem vários saberes como base para seu ofício (GAUTHIER et al., 2006).

Além disso, os referidos autores defendem um saber específico da classe profissional dos professores, que se refere ao saber da ação pedagógica. De acordo com os autores, esse saber é proveniente do saber experiencial do professor e dos demais saberes que, no entanto, deve ser público e testado em sala de aula. Assim, o saber da ação pedagógica é considerado como fundamental para a identidade profissional dos professores, que apesar de ser o saber menos desenvolvido, é o mais necessário para a profissionalização docente. Diante disso, é importante ressaltar que conhecer o conteúdo, ter talento, ter bom senso e experiência são indispensáveis à profissão docente. No entanto, os professores precisam refletir sobre a sua prática, lerem a realidade e lutarem para transformá-la, características que só podem ser conquistadas através da formação e da consciência dos saberes necessários à profissão, os quais são essenciais para um ofício que não seja vazio, mas repleto de saberes, conforme ressaltam Gauthier et al. (2006).

\section{Caminhos Metodológicos}

A investigação desenvolvida refere-se a uma abordagem de natureza qualitativa a qual, de acordo com Minayo (2007, p. 21):

Responde a questões muito particulares. (...) se preocupa, nas ciências sociais, com um nível de realidade que não pode ser quantificado. Ou seja, ela trabalha com o universo de significados, motivos, aspirações, crenças, valores e atitudes, o que corresponde a um espaço mais profundo das relações, dos processos e dos fenômenos que não podem ser reduzidos à operacionalização de variáveis.

Dessa maneira, este tipo de pesquisa exige um olhar específico às singularidades humanas, pois diz respeito à forma como os sujeitos vivem e encaram a vida. Tais aspectos 
devem ser levados em consideração, uma vez que atravessam a vida dos investigados, fazendo diferença no exercício de tentar compreender quem eles são, sem perder de vista que antes de serem sujeitos da pesquisa, são pessoas. A referida autora ainda afirma que a "análise qualitativa não é uma mera classificação de opinião dos informantes, é muito mais" (p. 27), pois na medida em que a fala dos sujeitos são ponderadas, abre-se um mundo de descobertas sobre o lugar de onde falam, que desvelam inúmeros significados, os quais devem ser observados à luz da teoria que dará suporte para que os fatos sejam refletidos de forma condizente com os moldes de pesquisa científica, permitindo a construção de conhecimento e o entendimento das especificidades humanas.

Dessa forma, os sujeitos dessa pesquisa foram cinco professoras integrantes de uma turma de 42 graduandos em Pedagogia do PARFOR/UESB, polo de Jaguaquara/BA, com idades variando entre 37 e 58 anos, sendo que todas elas dispunham de formação em nível médio, tendo feito o Curso Normal, também conhecido como Magistério. Elas atuavam há mais de três anos em turmas de alfabetização, tendo algumas delas mais de 20 anos de carreira no trabalho com turmas multisseriadas. Das cinco professoras entrevistadas, apenas uma já possuía formação em nível superior, sendo esta graduada em Psicologia.

Dessa maneira, a escolha dos sujeitos deu-se pelo fato de as informantes estarem buscando formação em nível superior. As professoras atuavam há anos na Educação Básica, mas ainda não possuíam formação inicial em nível superior prevista e exigida em Lei. Lembrando que, mesmo após a aprovação da referida Lei (BRASIL, 1996), a formação em nível médio continuou sendo aceita, devido a uma dualidade no texto da legislação, que previu a possibilidade de habilitação para o exercício da docência se dar nos dois níveis: no médio e no superior.

Utilizamos como principal dispositivo para a pesquisa a entrevista semi-estruturada, que versou sobre o processo de formação pedagógica dos sujeitos, bem como acerca da etapa de ensino/modalidade de atuação das professoras e o domínio de alguns conceitos como "alfabetização" e "letramento", os quais julgamos importantes para a realização da análise. Segundo Minayo (2007), a entrevista "é acima de tudo uma conversa a dois" (p. 64), que tem como objetivo "construir informações pertinentes para um objeto de pesquisa" (Idem). Diante disso, é possível afirmar, em concordância com a autora, que a entrevista representa uma conversa com intenções, intenções essas que possuem o objetivo de compreender uma determinada realidade.

Quanto às questões éticas relacionadas à pesquisa, durante todo o trabalho realizamos um esforço para guardarmos o anonimato das pessoas que, voluntariamente, se dispuseram a participar da investigação e, por isso, como forma de lhes assegurar esse direito, utilizamos no artigo nomes fictícios para nos referirmos aos sujeitos da pesquisa. Para tanto, escolhemos nome de flores conhecidas como suculentas, as quais são plantas de cultivo fácil e muito resistentes à seca, pois têm o potencial de acumular água em si, e embora sejam adaptadas a viver em lugares áridos e, por vezes, possuírem muitos 
- Revista de Iniciação à Docência, v. 5, n. 3, 2020 -

Publicação: março, 2021 - ISSN 2525-4332

espinhos, ainda assim, são capazes de produzir belíssimas flores (BRANCO, 2016). Dessa forma, atribuímos aos sujeitos aqui pesquisados os nomes de: Flor Estrela, Rosa de Pedra, Bálsamo, Flor de Maio e Jade.

A escolha desses nomes não se deu de forma aleatória, mas por meio de uma contextualização sensível às características marcantes das pessoas que foram entrevistadas, objetivando destacar o constante exercício de resiliência feito pelas professoras em suas vidas profissionais, que mesmo vivendo em meio a muitas dificuldades, desde o começo da sua escolarização até a formação em nível superior, tiveram muito que batalhar para conquistar seus objetivos e dar sua contribuição à educação de crianças, ao que atribuímos o significados da escolha do nome das flores.

\section{A formação do professor alfabetizador}

O professor alfabetizador é aquele que possibilita aos discentes que ainda não são alfabetizados se desenvolverem em relação à escrita e à leitura. Para tanto, necessita de uma formação sólida, que lhe permita se inteirar sobre o que é necessário para alfabetizar, como estratégias, conceitos e um método que ajude a sistematizar este ensino complexo, que envolve o domínio do código linguístico. Nesse sentido, é necessário aos docentes atuarem na alfabetização, conhecendo os diferentes ritmos de aprendizagem, bem como, de escrita, além de outros saberes dos estudantes.

\section{1 - Saberes docentes:}

Ao tratarmos dos saberes necessários à profissão docente, a trajetória das pessoas investigadas nos reporta inicialmente a pensar no que Gauthier et al. (2006) chamam de "um ofício sem saberes", considerando que algumas depoentes desta pesquisa se encontravam há mais de 20 anos em sala de aula, porém sem possuírem efetivamente a formação necessária para estarem ali, o que certamente lhes possibilitava ter um ofício, mas não necessariamente dominarem os saberes indispensáveis para uma boa atuação.

De acordo com os referidos autores, um ofício sem saberes caracteriza-se por resumir o ato de ensinar apenas a conhecer o conteúdo, ter talento, bom senso, experiência ou apenas seguir a sua própria intuição. No entanto, o que realmente caracteriza a profissionalização docente são os saberes profissionais específicos, que não desconsideram os aspectos anteriormente citados, mas que precisam ser mobilizados a fim de se ter um ofício realmente feito de saberes. Dessa maneira, entendendo essa realidade, nos atentamos às falas das entrevistadas, a fim de percebermos os saberes por elas mobilizados durante os seus anos de atuação.

Em relação aos saberes docentes, Flor Estrela ressaltou que "você tem que saber o que está fazendo e (se perguntar) qual a finalidade disso que eu vou fazer? Principalmente em relação à criança, a questão da rotina, da ludicidade [...]" (Flor Estrela, 2018). De acordo com a fala dessa colaboradora, o professor deve estar atento às questões relacionadas às crianças, às suas rotinas, que devem ser desenvolvidas na sala de aula, que são saberes 
imprescindíveis para a prática docente, principalmente quando se trata da Educação Infantil, visto que é uma etapa que requer aprofundamento em relação a esses saberes, que não são encontrados em qualquer lugar, mas dizem respeito especificamente ao curso de Pedagogia, o responsável por essa formação.

De acordo com Tardif (2014), os saberes citados pela professora referem-se aos saberes da formação profissional, os quais deveriam ser "transmitidos pelas instituições de formação de professores (escolas normais ou faculdades de ciências da educação)" (TARDIF, 2014, p. 36) e apresentados aos professores durante sua formação pedagógica, a fim de subsidiar um uso específico que, neste caso, é aplicado dentro da área de Educação Infantil. Esses saberes, portanto, são saberes científicos, imprescindíveis para a atuação dos professores. São saberes que precisam ser mobilizamos para uma atuação efetiva em cada área a que são destinados.

Quando questionada sobre os saberes necessários aos professores, Bálsamo respondeu que se utiliza da sua experiência e a partir da prática na sala de aula e do perfil da turma, que é descoberto através de um diagnóstico. Com isso, ela determina o que pode ensinar a cada um dos discentes, conforme destacou em um trecho da entrevista:

\section{Eu vou aprendendo ali na sala com as crianças, principalmente no início do ano, que eu digo "essa turma vai ser minha esse ano". Então a gente faz aquele diagnóstico. Dessa forma que eu vou captando o que eles sabem, para eu saber o que eu posso jogar para cada um (Bálsamo, 2018).}

Diante disso, verificamos que a docente se utiliza do saber experiencial que, segundo Tardif (2014), é o saber obtido através da prática cotidiana, o qual é construído pelos próprios professores. De acordo com Gauthier et al. (2006, p. 22-23):

De fato, aprender através de suas próprias experiências significa viver um momento particular, momento esse diferente de tudo o que se encontra habitualmente, sendo registrado como tal em nosso repertório de saberes. Essa experiência tornase então "a regra" e, ao ser repetida assume muitas vezes a forma de atividade de rotina.

Dessa maneira, este saber é encontrado em todos os professores em exercício que, a partir da sua prática cotidiana, se utilizam de saberes construídos por si mesmos. Essa modalidade de saber recebe destaque da professora Flor de Maio que, no início da carreira, após a formação no magistério, disse não ter nenhuma experiência prática e que foi "[...] aprendendo no dia a dia, procurando... fui perguntando as outras professoras que ensinavam, ia para casa delas [...]" (Flor de Maio, 2018). Portanto, quando teve sua primeira turma, a referida professora, além de aprender no dia a dia da sala de aula, buscou junto aos professores mais experientes informações, a fim de ter auxílio quanto ao saber fazer.

No caso de Flor de Maio, é possível afirmar que ela teve êxito em buscar os saberes da experiência de outros professores para lhe ajudar a desenvolver sua prática. No entanto, nem sempre isso é possível, pois, de acordo com Gauthier et al. (2006), "embora o professor viva muitas experiências das quais tira grande proveito, tais experiências, infelizmente, permanecem confinadas aos segredos da sala de aula" (p. 23). Assim, esses 
saberes que, geralmente, também podem ser classificados como importantes, são construídos no "chão da escola" como resultado de uma prática de muitos anos. Às vezes são levados para o túmulo dos docentes, que por guardarem tamanho segredo, não dão oportunidade de que eles sejam testados cientificamente, limitando-os a si mesmos.

\section{2 - O processo de formação acadêmica e o exercício de reflexão sobre a prática:}

Nesta seção focalizamos o processo de formação acadêmica pelo qual passaram os sujeitos pesquisados no curso de Pedagogia oferecido pelo PARFOR/UESB, polo de Jaguaquara, avaliando a sua contribuição na revisão das práticas dessas professoras. Nesse sentindo, é oportuno lembrar que as professoras entrevistadas já possuíam formação em nível médio, referente ao Curso de Magistério e há anos atuavam em sala de aula, o que antecipadamente nos levou a entender que a formação em nível superior certamente lhes proporcionaria perspectivas diferentes em relação à profissão docente, conforme veremos a seguir. De acordo com os relatos das professoras, nos foi possível extrair de suas falas as contribuições que o curso de graduação porventura tenha lhes proporcionado, considerando a revisão das práticas que algumas delas mencionam.

A gente vai fazer uma leitura e fala: "meu Deus!". Fazemos uma reflexão. Me pergunto: O quê que eu tenho feito? Será que eu estou indo pelo caminho certo? Vou mudar? Vou ver o que a professora falou, vou aplicar na minha sala [...]. Então assim, é a questão de se reinventar todo dia. Por isso eu acho que tem me possibilitado a reflexão em relação à prática (Jade, 2018).

Conforme mostra o relato acima, sugerimos que através da teoria oferecida pelo curso, os professores tiveram a oportunidade de repensar a sua prática, analisando se os caminhos que têm tomado para ensinar são pertinentes ou se precisam ser alterados, levando-os ao exercício da reflexão que, como foi ressaltado por Jade, possibilita-os reinventarem-se. Além disso, essa fala da colaboradora, que se referiu às leituras proporcionadas pelo curso e às aulas ministradas pelos professores formadores, nos levou entender que o conhecimento teórico oferecido pela graduação ajudou os educadores atuantes em sala de aula não só a pensar sobre o que têm feito, como também a ponderar sobre a necessidade de modificar a sua atuação, com base nos conhecimentos teóricos que foram oferecidos.

Sobre a relação entre teoria e prática Schmidt, Ribas e Carvalho (2003) afirmam que "as teorias são como mapas que nos ajudam a viajar sobre o momento presente para auscultar a realidade, o que não se faz sem a história. O que se busca, na verdade, é a construção de uma prática pedagógica reflexiva, crítica e criativa" (p. 28). Então, esse exercício de reflexão, que também foi mencionado pela colaboradora, é fator importante que destacamos e que esteve presente também em outras falas, sendo mencionado, por exemplo, pela Prof ${ }^{a}$ Flor Estrela, ao apontar o seguinte argumento:

Você vê e ouve o que o professor passa e vai vendo que aquilo que você faz não está bem adequado, aí tenta mudar. Quando você vai para sua escola, para sala de aula, lembra daquilo que o professor falou

(Flor Estrela, 2018). 
Dessa maneira, foi possível perceber que esse exercício feito pela colaborada é fundamental, pois professor que não reflete sobre sua prática não consegue se reinventar. Pelo contrário, a falta de reflexão sobre a atuação e o ensino que tem oferecido às pessoas pode fazer da sua atuação docente apenas uma atividade mecânica e rotineira, que consideramos como uma visão a ser superada. Nesse sentido, Alonso (2003) afirma que:

O professor necessita de muito mais do que a intuição para proceder à reflexão sobre sua prática: ele precisa estar preocupado com o aluno mais do que com o conhecimento a ser transmitido, com as suas reações frente a esse conhecimento, com os seus propósitos em termos de ensino e aprendizagem e estar consciente de suas responsabilidades nesse processo (p. 15).

Dessa forma, é essencial no exercício da reflexão que os docentes entendam a sua responsabilidade frente ao processo educacional dos sujeitos, assumindo a sua postura como formador que precisa mediar a aprendizagem, dominando não só os conteúdos, mas através de um olhar sensível e uma percepção crítica, entender as dimensões socioculturais dos educandos. Diante disso, o professor terá que se colocar:

[...] em uma posição de pesquisar (deixando de lado a sua participação como ator do processo), que busca compreender e analisar os fenômenos que observa, com o objetivo de encontrar não só respostas às perguntas que ele se faz e possíveis encaminhamentos, como também soluções para as dificuldades constatadas (ALONSO, 2003, p. 15-16).

Assim, vale a pena ressaltar que essas possíveis soluções não podem ser encontradas individualmente, apenas pela reflexão isolada do professor, mas necessitam da luz da teoria, em concordância com a percepção do professor crítico-reflexivo. Ainda sobre isso, também podemos perceber a temática da reflexão presente em assuntos mais específicos, trazidos por Jade, como em relação à avaliação da aprendizagem:

\section{Na questão da avaliação dos alunos deixou outro olhar. Como é que eu estou avaliando meus alunos? Estou riscando a prova deles? Estou circulando, para chocar? Isso é bom ou, não é? Vamos rever a prática. Então assim, tem me ajudado muito e contribuído muito para minha prática (Jade, 2018).}

Diante da fala de Jade, foi possível perceber que o curso lhe possibilitou repensar alguns processos sobre avaliação da aprendizagem, o que consideramos como uma tarefa necessária à prática docente, tendo em vista que o ato de avaliar vai muito além da simples atribuição de notas, pois tem o poder de aprovar ou reprovar alguém, resumindo muitas vezes o ser humano a dados quantitativos que não levam em conta os pequenos avanços, mas atenta-se apenas às médias estabelecidas, constituindo-se, portanto, como um processo que indubitavelmente precisa ser repensado pelos professores.

De acordo com Luckesi (2005), a forma errônea com a qual os professores lidam com os processos de avaliação pode ser justificada, devido à atual prática da avaliação escolar estipular como função do ato de avaliar:

[...] a classificação e não o diagnóstico, como deveria ser constitutivamente. Ou seja, o julgamento de valor, que teria a função de possibilitar uma nova tomada de decisão sobre o objeto avaliado, passa ter 
- Revista de Iniciação à Docência, v. 5, n. 3, 2020 -

Publicação: março, 2021 - ISSN 2525-4332

função estática de classificar um objeto ou um ser humano histórico num padrão definitivamente determinado (LUCKESI, 2005, p. 34).

Diante disso, é preciso que os professores e os cursos de formação continuem a refletir sobre os processos de avaliação, a fim de que eles se posicionem "a serviço de uma pedagogia que entenda e esteja preocupada com a educação como mecanismo de transformação social” (LUCKESI, 2005, p. 28). Dessa forma, a avaliação escolar deve visar o crescimento, a autonomia e a transformação dos educandos e não o seu retrocesso.

Outro assunto suscitado nas entrevistas encontra-se identificado na fala da Prof. ${ }^{a}$ Flor Estrela, ao nos relatar o seguinte aspecto de suas experiências:

Antes de eu estar no PAFOR, tive um aluno com dislexia e eu não sabia o que era dislexia; não tenho vergonha de dizer que eu não sabia, não tenho. No PARFOR eu me descobri! Eu ainda tenho que estudar mais para saber essa questão de dificuldades de aprendizagem, mas já é diferente, porque antes eu não sabia e eu não buscava [...] (Flor Estrela, 2018).

A partir do curso, a professora passou a buscar compreender o que antes não sabia, como o entendimento de aspectos sobre os distúrbios de aprendizagem, que é um conhecimento imprescindível para quem está atuando na sala de aula, tendo em vista a heterogeneidade presente em todo e qualquer espaço escolar. Essa heterogeneidade nos revela que as crianças aprendem de forma diferenciada e possuem formas distintas para se desenvolver. Tendo em vista isso, a fala da colaboradora Flor de Maio nos sugere que o curso também contribuiu nesse aspecto:

Cada um tem seu tempo e a gente acha que não. Quando estamos na sala, todos têm que ter o mesmo tempo. Em relação a isso, o curso fez a gente ter outro olhar, porque nem todos aprendem ao mesmo tempo! E hoje eu já entendo (Flor de Maio, 2018).

Destarte, a formação obtida parece ter contribuído para a mudança de olhar sobre a heterogeneidade dos alunos na sala de aula e sobre o tempo da criança e o tempo de aprender, que são diferentes. Um conhecimento totalmente necessário ao professor que necessita entender que os discentes aprendem de forma diferente e avançam em um tempo determinado por seu próprio processo de desenvolvimento, principalmente no tempo em que vivemos quando a diferença é motivo de preocupação.

De acordo com Mantoan (2003)5, "nas salas de aula em que o ensino é para todos, o saber não é disposto pelo discurso do professor e o conhecimento não é transmitido" (s. p.), pois tendo em vista a heterogeneidade dos alunos, o professor precisa utilizar uma linguagem acessível e agir de forma que o conhecimento beneficie a todos, oportunizando a cada um dos educandos aprenderem conforme o seu ritmo e interesse. Nesse sentido, a autora reitera que os obstáculos a serem vencidos:

[...] são de natureza subjetiva e, a nosso ver, são os mais fortes, pois dizem respeito a questões que estão arraigadas a nossa formação e a experiências

\footnotetext{
${ }^{5}$ Referência ao texto "Por uma escola para todos". Disponível em: < http://www.lite.fe.unicamp.br/cursos/nt/ta1.13.htm. Acesso em 14 de mai. 2020.
} 
- Revista de Iniciação à Docência, v. 5, n. 3, 2020 -

Publicação: março, 2021 - ISSN 2525-4332

pessoais em uma sociedade que não está habituada a reconhecer e a valorizar as diferenças (MANTOAN, 2003, [s.p.]).

Portanto, é evidente que só conhecer essa temática não basta, é preciso ir além, porque, apesar da formação já dar conta desse suporte teórico sobre as diferenças na sala de aula, ainda temos muito a caminhar em relação a isso, para que o direito à educação seja efetivado a toda e qualquer pessoa. Dessa forma, a autora ${ }^{6}$, ainda afirma que:

[...] a proposta de se ensinar a turma toda, independentemente das diferenças de cada um dos alunos, implica a passagem de um ensino transmissivo para uma pedagogia ativa, dialógica, interativa, conexional, que se contrapõe a toda e qualquer visão unidirecional, de transferência unitária, individualizada, hierárquica do saber (MANTOAN, 2003, [s.p.]).

Decerto, não há dúvidas de que ainda é preciso que a formação se debruce sobre essa pedagogia ativa, assim como os profissionais da educação, a fim de torná-la realidade em todas as escolas, superando seus próprios limites e, principalmente, qualquer diferença, independente da sua ordem, já que uma educação gratuita e de qualidade para todos requer um ensino que também aconteça efetivamente para todos.

Posto isso, entendemos, em relação à fala das colaboradoras, que um conhecimento tão importante como esse não era dominado pelas mesmas, visto que, os estudos sobre a diferença no Brasil tomaram impulso a partir da LDB (1996), sendo que depois disso, vários documentos foram produzidos e divulgados pelo Ministério da Educação e por especialistas na área, os quais reafirmavam o disposto na lei e estabeleceram as diretrizes para a inclusão de pessoas com deficiência, transtornos globais do desenvolvimento, altas habilidades/superdotação nas escolas comuns.

[...] um documento intitulado de "O Acesso de Alunos com Deficiência às Escolas $e$ Classes Comuns da Rede Regular" com o objetivo de disseminar os conceitos e diretrizes mundiais para a inclusão, reafirmando o direito e os benefícios da escolarização de alunos com e sem deficiência nas turmas comuns do ensino regular (BRASIL, 2007, grifo nosso).

Tudo isso nos leva a entender que antes de documentos como esses lançarem luz sobre a temática da inclusão, a formação em nível médio não dava conta de formar os professores em relação à educação inclusiva, pensando na inserção de todo e qualquer sujeito na escola, fazendo com que esse conhecimento fosse acessado pela maioria das colaboradoras apenas na Educação Superior, neste caso, estudando no curso de Pedagogia. Assim, os fatos mencionados e as falas das professoras nos sugerem muitos pontos positivos sobre a formação oferecida pelo referido curso, possibilitando, além de (re)significar as práticas das professoras em relação aos conceitos teóricos que elas já dominavam, também inserir essas profissionais em novas realidades do campo educacional, o que consideramos essencial para a continuidade da formação docente, já

\footnotetext{
${ }^{6}$ Referência ao texto "Ensinando a turma todo - as diferenças na escola". Disponível em: $<$ http://www.lite.fe.unicamp.br/papet/2003/ep403/ensinando_a_turma_toda.htm> Acesso em 14 de mai. 2020.
} 
- Revista de Iniciação à Docência, v. 5, n. 3, 2020 -

Publicação: março, 2021 - ISSN 2525-4332

que elas tiveram a oportunidade não só de rever, como também de adquirir conhecimentos que ainda não possuíam.

\section{Considerações finais}

A pesquisa teve como desafio responder à seguinte questão: como o PARFOR contribuiu com a formação profissional das professoras alfabetizadoras?

Dessa forma, em nossas considerações finais pretendemos, ao fazer essa retomada, apresentar os resultados obtidos no decorrer da investigação. Nesse sentindo, é possível afirmar que o curso de Pedagogia oferecido pelo PARFOR/UESB, polo de Jaguaquara/BA, possibilitou aos estudantes muitas contribuições, imprescindíveis para que elas revissem algumas de suas práticas, permitindo que mudanças fossem efetivadas em seus campos de atuação. Dessa forma, o estudo revelou que essas contribuições se referem à aquisição de saberes necessários à profissão docente pelos professores, como também um novo olhar sobre o processo de avaliação das crianças e sobre o desenvolvimento de seus alunos, que se dá de forma diferenciada.

Ademais, a teoria oferecida pela formação no curso permitiu que os docentes que já possuíam formação em nível médio (re)significassem as suas práticas, o que consideramos primordial a todos os discentes do curso, principalmente em relação ao professor alfabetizador, que foi o sujeito de nossa pesquisa. Diante disso, retomaremos as questões que nortearam nosso trabalho, a fim de melhor expor nossas conclusões temporariamente.

Em relação à formação profissional obtida e à revisão das práticas dos professores, descobrimos que os anos de prática não foram suficientes para as docentes aqui investigadas, assim, Ihes foi necessária a formação inicial, não apenas pela obrigatoriedade da legislação, mas devido às suas necessidades de dialogarem com novas teorias, sendo possível constatar isso devido às contribuições destacadas pelas colaboradoras em seus relatos a respeito da possibilidade que tiveram de rever a prática que por muitos anos lhe acompanhava.

Isso posto, pontuamos que o curso contribuiu para o desenvolvimento profissional das professoras à medida que Ihes proporcionou conhecimentos cruciais para quem tem a tarefa de alfabetizar. Os relatos das professoras nos levam a entender que antes da graduação, elas não refletiam sobre a sua atuação em sala de aula, ocasionando práticas docentes cristalizadas e atividades repetitivas. A partir do contato com a teoria proporcionado pelo curso, as docentes tornaram-se mais atentas às suas atuações profissionais, pois começaram a relacionar a teoria com a prática, conforme relataram em suas entrevistas. 
Assim, foi possível às alfabetizadoras, além de refletir sobre a prática, modificar ações que lhes eram rotineiras, mudando estratégias que tinham para ensinar, que eram utilizadas há longos períodos, como repensar o processo de avaliação, que era visto por algumas colaboradoras como exercício para classificar os alunos, mas que a partir da construção feita na graduação as docentes passaram a enxergá-la, de modo a levar em consideração o desenvolvimento dos alunos, considerando seus avanços.

Nessa mesma perspectiva, também entendemos como contribuição do curso a forma pela qual as professoras passaram a enxergar a heterogeneidade presente na sala de aula, abandonando um determinado padrão de ação em relação à aprendizagem dos alunos, para abrir espaço à diferença de tempo que as crianças possuem para aprender que, por vezes, foi entendida por elas como falta de interesse dos educandos, o que mudou depois da formação.

Quanto à contribuição oferecida pelo PARFOR em relação aos saberes voltados à formação do professor alfabetizador, podemos afirmar que o curso permitiu às docentes tanto rever os seus saberes experienciais, já utilizados em sala de aula, como também adquirir novos saberes, como os saberes da formação profissional oferecidos pelo curso, que são os saberes científicos ofertados através das aulas teóricas realizadas na graduação, os quais foram essenciais para a atuação das professoras, assim como o saber experiencial que, a partir da formação, elas puderam transformar por meio da reflexão já mencionada.

\section{Referências}

ALONSO, M. (Org.). O trabalho docente: teoria e prática. São Paulo/SP: Pioneira, 2003.

BRANCO, A. 10 espécies de cactos e plantas suculentas fáceis de cultivar e manter. 2016. Disponível em: https://www.greenme.com.br/morar/horta-e-jardim/4731-10-especies-de-cactos-da-cultivar . Acesso em 06 de dez. 2018.

BRASIL. Ministério de Educação e Cultura. LDB. Lei n. 9394/96, de 20 de dezembro de 1996. Estabelece as diretrizes e bases da Educação Nacional. Brasília/DF: MEC, 1996.

. Plano Nacional de Formação de Professores da Educação Básica - PARFOR. 2018. Disponível em: <http://www.capes.gov.br/educacao-basica/parfor> Acesso em: 15 de out de 2018.

. A capes e a educação básica. 2014. Disponível em:

<http://www.capes.gov.br/acessoainformacao/informacoes-classificadas/57-salaimprensa/artigos/4721-a-capes-e-a-educacao-basica> Acesso em: 15 de out de 2018.

. Analfabetismo cai em 2017 mas segue a cima da meta para 2015. 2018. Disponível

em: <https://agenciadenoticias.ibge.gov.br/agencia-noticias/2012-agencia-de-noticias/noticias/21255-analfabetismo-cai-em-2017-massegue-acima-da-meta-para-2015>. Acesso em: 27 de nov de 2018.

- Secretaria de Educação Especial. Política Nacional de Educação Especial na Perspectivada Educação Inclusiva. Brasília/DF. [Documento elaborado pelo Grupo de Trabalho nomeado pela portaria n. 555/2007, prorrogada pela portaria n. 948/2007, entregue ao ministro da Educação em 7 de janeiro de 2008]. Disponível em: <http://peei.mec.gov.br/arquivos/politica_nacional_educacao_especial.pdf> Acesso em: 05 de nov. de 2018. 
- Revista de Iniciação à Docência, v. 5, n. 3, 2020 -

Publicação: março, 2021 - ISSN 2525-4332

GATTI. A. B. Formação de professores no Brasil: características e problemas. Educação \& Sociedade, v. 31, n. 113, 2010, p. 1355-1379.

GAUTHIER, C. et al. Por uma teoria da pedagogia: pesquisas contemporâneas sobre o saber docente. 2. ed. Ijuí/RS: Editora Unijuí, 2006.

LUCKESI, C. Avaliação da aprendizagem escolar. São Paulo/SP: Cortez, 2005.

MANTOAN, M. T. E. Por uma escola de todos. LITI UNICAMP. [S.I] [2003]. Disponivel em: <http://www.lite.fe.unicamp.br/cursos/nt/ta1.13.htm> Acesso em: 14 de mai. 2020.

. Ensinando à turma toda: as diferenças na escola. LITI UNICAMP. [S.I.] [2003]. Disponível em: <http://www.lite.fe.unicamp.br/papet/2003/ep403/uma_escola_de_todos.htm> Acesso em 14 de mai. 2020.

MINAYO, M. C. L. (Org.) Pesquisa social: teoria, método e criatividade. Petrópolis/RJ: Vozes, 2007.

SAVIANI, D. Formação de professores: aspectos históricos e teóricos do problema no contexto brasileiro. Revista Brasileira de Educação, v. 14, n. 40, 2009, p. 143-155.

SCHMIDT, L. M.; RIBAS, M. H.; CARVALHO, M. A. A prática pedagógica como fonte de conhecimento. In: ALONSO, M. (Org.). O trabalho docente: teoria e prática. São Paulo/SP: Pioneira Thomson Learning, 2003, p. 19- 36.

TARDIF, M. Saberes docentes e formação profissional. Petrópolis/RJ: Vozes, 2014. 